\title{
Sex ratio in relation to fathers' occupations
}

\author{
Heather O Dickinson, Louise Parker
}

\begin{abstract}
Objective-To investigate whether the sex ratio of children varies between fathers of different occupations.
\end{abstract}

Methods-The sex ratio (the ratio of the number of boys to the number of girls at birth) was calculated in relation to paternal occupation in the cohort of all 253433 live births in Cumbria, north west England, from 1950-89. Exact binomial confidence intervals were used to estimate whether the sex ratio in each occupational category was significantly different from that for the rest of the cohort.

Results-There were fewer occupational categories with significantly different sex ratios at the $5 \%$ level than expected by chance alone, assuming the same binomial distribution of sexes at birth within each paternal occupation.

Conclusions-Significant variation of the sex ratio with fathers' occupations was not found. There is some evidence that the sex ratio shows less variance than expected under a binomial model which assumes independence of the sex of each child; a possible explanation of this may be parental preference for limiting family size after children of both sexes have been born or some other factor which results in children within a family being more likely to be of both sexes rather than the same sex.

(Occup Environ Med 1997;54:868-872)

Keywords: sex ratio; cohort; paternal occupation

University of

Newcastle, North of

England Children's

Cancer Research Unit,

Department of Child

Health, Royal Victoria

Infirmary, Queen

Victoria Road,

Newcastle upon Tyne,

UK

H O Dickinson

L Parker

Correspondence to: Dr HO Dickinson, University of Newcastle,

North of England Children's Cancer Research Unit,

Department of Child Health

Royal Victoria Infirmary,

Queen Victoria Road,

Newcastle upon Tyne NE1

4LP, UK. Tel: 0044191202

3035; Fax: 0044191202

3060; E-mail:

heather.dickinson@ncl.ac.uk

Accepted 10 July 1997
There has been speculation that the sex ratio (the ratio of the number of male births to the number of female births) varies with fathers' occupations, possibly due to the effect of occupational exposures. ${ }^{1-9}$ This has been explored in the cohort of all live births in Cumbria, north west England, between 1950 and 1989.

\section{Methods}

A database was constructed comprising birth registration data of all 263949 live births to mothers domiciled in Cumbria between 1 January 1950 and 30 September $1989 .{ }^{10}$ The fathers' occupations, as recorded on the birth registration, were coded. ${ }^{11}$ The 10516 live births for which the father was not recorded on the birth registration, or for which his occupation was not noted or could not be coded, were excluded from the study. The sex ratio was calculated for children fathered by men in various occupational categories. $95 \%$ Confidence intervals $(95 \% \mathrm{CIs})$ on the sex ratio were calcu- lated with the exact binomial method as implemented by the statistical software package Stata. ${ }^{12}$ The numbers of male and female births to fathers in each occupational category were compared with those for the rest of the cohort with the $\chi^{2}$ test, yielding significance levels which should be valid except for categories with small numbers of births. Where the trend of sex ratio with time was of interest, this was estimated with logistic regression. ${ }^{12}$ These statistical tests are based on the assumption that the sex of each birth is independent.

The results were compared with those of McDowall, ${ }^{1}$ who calculated the sex ratio in relation to paternal occupational category in a study of over 190000 births comprising a random $10 \%$ sample of births from 1980-2 in England and Wales and drew attention to various occupational categories which produced children of a low sex ratio not only in his study but also in an unpublished study of all 601526 births in England and Wales in 1978. As he used an earlier classification system ${ }^{13}$ to code occupations, we determined which occupational code of the more recent system $^{11}$ corresponded most closely to the older occupational categories before calculating the sex ratios for them.

Meta-analyses of the results presented by McDowall for 1978 and 1980-2 and those of the current study were carried out, having first checked that there was no significant difference between the overall sex ratios in the three periods. As the periods studied by McDowall overlapped with the current study, the small numbers of overlapping children were estimated and appropriate adjustment was made.

\section{Results}

The 253433 children in the study group had a sex ratio of 1.056 ( $95 \%$ CI 1.048 to 1.064$)$ and their fathers fell into 367 unique occupational categories. Without making any allowance for multiple testing, the sex ratio was significantly different $\left(\mathrm{P}<0.05\right.$ with the $\chi^{2}$ test) from that for the rest of the cohort in $14(4 \%)$ of these occupational categories (table 1). However, for three of these categories, officers in foreign armed forces, domestic housekeepers, and road sweepers, the $95 \%$ confidence interval derived with exact binomial methods overlapped the $95 \% \mathrm{CI}$ of the sex ratio for the entire cohort, implying that the borderline significance $(\mathrm{P}=0.041,0.050$, and 0.042 respectively) obtained from the $\chi^{2}$ test was probably not valid for these small samples $(13,7$, and 35 children respectively). These three categories should therefore not be regarded as being significantly different from the rest of the 
Table 1 Live births in Cumbria, 1950-89: paternal occupations for which the sex ratio was significantly different from that for the rest of the cohort on the basis of $a \chi^{2}$ test

\begin{tabular}{|c|c|c|c|}
\hline Occupational code and category ${ }^{t I}$ & $\begin{array}{l}\text { Births } \\
(n)\end{array}$ & $\begin{array}{l}\text { Sex ratio ( } 95 \% \text { CI - exact } \\
\text { binomial) }\end{array}$ & $\begin{array}{l}P \text { value from } \\
\chi^{2} \text { test }\end{array}$ \\
\hline \multicolumn{4}{|l|}{151 Officers in foreign and } \\
\hline commonwealth armed forces & 13 & $0.300(0.053$ to 1.165$)$ & $0.041 \dagger$ \\
\hline 211 Mechanical engineers & 1504 & $1.225(1.105$ to 1.358$)$ & 0.004 \\
\hline 300 Laboratory technicians & 973 & $1.237(1.088$ to 1.407$)$ & 0.014 \\
\hline $\begin{array}{l}512 \text { Grinding machine setters and } \\
\text { setter-operators }\end{array}$ & 57 & 2167 (1) 210 to 4020 & 0.010 \\
\hline 532 Plumbers, heating and ventilating & כr & $2.100(1.21004 .020)$ & 0.010 \\
\hline engineers and related trades & 3696 & $0.973(0.912$ to 1.039$)$ & 0.013 \\
\hline 581 Butchers, meat cutters & 1375 & $1.193(1.071$ to 1.329$)$ & 0.024 \\
\hline $\begin{array}{l}670 \text { Domestic housekeepers and related } \\
\text { occupations }\end{array}$ & 7 & $0.167(0.004$ to 1.370$)$ & $0.050 t$ \\
\hline $\begin{array}{l}733 \text { Scrap dealers, scrap metal } \\
\text { merchants }\end{array}$ & 474 & $1.268(1.054$ to 1.527$)$ & 0.047 \\
\hline 851 Assemblers and line workers & & & \\
\hline (vehicles and other metal goods) & 168 & $1.471(1.070$ to 2.032$)$ & 0.034 \\
\hline $\begin{array}{l}873 \text { Bus and coach drivers } \\
899 \text { Other plant and machine operatives }\end{array}$ & 1669 & $0.941(0.853$ to 1.037$)$ & 0.018 \\
\hline $\begin{array}{l}\text { not elsewhere classified } \\
902 \text { All other occupations in farming }\end{array}$ & 2005 & $0.965(0.884$ to 1.053$)$ & 0.039 \\
\hline and related ${ }^{\star}$ & 389 & $1.329(1.083$ to 1.635$)$ & 0.024 \\
\hline 957 Road sweepers & 35 & $2.182(1.028$ to 4.935$)$ & $0.042 \dagger$ \\
\hline 958 Cleaners, domestic workers & 298 & $0.828(0.654$ to 1.047$)$ & 0.036 \\
\hline
\end{tabular}

*Excluding farm workers and agricultural machinery drivers and operatives.

$\dagger$ Not significantly different from the rest of the cohort on the basis of exact binominal CI.

cohort, leaving the sex ratio significantly different in 11 occupational categories.

Table 2 shows that $\mathrm{McDowall}^{1}$ noted four groups of paternal occupational categories: warehousemen, textile workers, United Kingdom armed forces, and food and drink workers other than bakers and butchers, for which the sex ratio of the offspring was non-significantly lower than that for the rest of the cohort not only in his study of 1980-2, but also in the study of births in 1978. In the present study, the sex ratio for warehousemen was nonsignificantly higher than that for the rest of the cohort, and the sex ratio for the other three groups was non-significantly lower. For these four groups the results of the present study were combined with those from both the 1980-2 study and the 1978 study but in the combined sample none of these occupational groups had children with a significantly lower sex ratio (table 2 ).

McDowall ${ }^{1}$ highlighted as deserving further study four other groups: road transport drivers, welders, railway workers, and medical radiographers, which had children with a sex ratio lower than the national sex ratio in his 1980-2 study, although in only one group, children of railway workers, was this significant $(P<0.01)$. In the present study, the sex ratio for children of road transport drivers was non-significantly lower than that for the rest of the cohort, whereas that for the other three groups was non-significantly higher. As before, for these four groups the results of the present study were combined with those from the 1980-2 study (the raw data from the 1978 study not being available for these groups); again none of the occupational groups in the combined sample had children with a significantly lower sex ratio (table 2 ).

It has been suggested that butchers fathered more girls than expected in the period from the 1950 s to the middle of the 1970 s, when oestrogenic hormones were used as growth promoters in cattle, but more boys in the following period when androgens were used instead. ${ }^{6}$ This hypothesis was not supported by the present study: the sex ratio of children born to butchers during the periods $1950-70$ and $1980-9$ was 1.169 (95\% CI 1.017 to 1.345$)$ and 1.398 (95\% CI 1.103 to 1.777 ) respectively, showing no significant difference

Table 2 Selected paternal occupations and groups of paternal occupations highlighted by McDowall as having a low sex ratio

\begin{tabular}{|c|c|c|c|c|}
\hline Occupational codes $t$ & Group of occupational categories & Births (n) & $\begin{array}{l}\text { Sex ratio ( } 95 \% C I \text { - exact } \\
\text { binomial) }\end{array}$ & $\begin{array}{l}P \text { value from } \\
\chi^{2} \text { test }\end{array}$ \\
\hline \multicolumn{5}{|c|}{ Current study (sex ratio of entire cohort, 1.056 ( $95 \%$ CI 1.048 to 1.064 ): } \\
\hline 441 & Storekeepers and warehousemen & 3137 & $1.079(1.005$ to 1.158$)$ & $0.546 \mathrm{NS}$ \\
\hline $550-553,559,811-814$ & Textile workers & 2618 & $1.022(0.945$ to 1.104$)$ & $0.395 \mathrm{NS}$ \\
\hline 600,601 & Officers, UK armed forces & 4743 & $1.052(0.994$ to 1.115$)$ & $0.905 \mathrm{NS}$ \\
\hline \multirow[t]{2}{*}{582,809} & Food and drink workers (other & & & \\
\hline & than bakers and butchers $) \ddagger$ & 1231 & $1.018(0.909$ to 1.140$)$ & $0.520 \mathrm{NS}$ \\
\hline $872,873,874$ & Road transport drivers & 14353 & 1.034 (1.000 to 1.068$)$ & $0.186 \mathrm{NS}$ \\
\hline 537 & Welders & 2834 & $1.058(0.982$ to 1.140$)$ & $0.957 \mathrm{NS}$ \\
\hline $881-884$ & Railway workers & 3375 & $1.082(1.011$ to 1.158$)$ & $0.476 \mathrm{NS}$ \\
\hline 342 & Medical radiographers & 85 & $1.073(0.685$ to 1.684$)$ & $0.941 \mathrm{NS}$ \\
\hline \multicolumn{5}{|c|}{ McDowall's $1980-2$ study (sex ratio of entire cohort, 1.052 (95\% CI 1.043 to 1.062 ): } \\
\hline 333 & Storekeepers, warehousemen & 3017 & $0.999(0.930$ to 1.074$)$ & $0.155 \mathrm{NS}$ \\
\hline $176-183,199,289,339$ & Textile workers & 1941 & $1.030(0.942$ to 1.127$)$ & $0.644 \mathrm{NS}$ \\
\hline 135 & Officers, UK armed forces & 3663 & $0.998(0.935$ to 1.066$)$ & $0.109 \mathrm{NS}$ \\
\hline 187,202 & Food and drink workers (other & & & \\
\hline $325-327$ & $\begin{array}{l}\text { than bakers and butchers) } \\
\text { Road transport drivers }\end{array}$ & $\begin{array}{l}1034 \\
8381\end{array}$ & $\begin{array}{l}0.947(0.837 \text { to } 1.072) \\
1.024(0.981 \text { to } 1.069)\end{array}$ & $0.204 \mathrm{NS}$ \\
\hline 265 & Welders & 2048 & $0.984(0.902$ to 1.075$)$ & $0.131 \mathrm{NS}$ \\
\hline $319-322$ & Railway workers & 479 & $0.842(0.700$ to 1.012$)$ & $0.015^{\star}$ \\
\hline 45 & Medical radiographers & 31 & $0.842(0.376$ to 1.775$)$ & $0.496 \mathrm{NS}$ \\
\hline \multicolumn{5}{|c|}{ Meta-analysis of current study, McDowall's $1980-2$ study, and 1978 study: } \\
\hline & Storekeepers and warehousemen & 6125 & $1.038(0.987$ to 1.092$)$ & $0.547 \mathrm{NS}$ \\
\hline & Textile workers & 4537 & $1.025(0.967$ to 1.087$)$ & $0.348 \mathrm{NS}$ \\
\hline & Officers, UK armed forces & 8391 & $1.029(0.985$ to 1.074$)$ & $0.258 \mathrm{NS}$ \\
\hline & $\begin{array}{l}\text { Food and drink workers (other } \\
\text { than bakers and butchers) } \pm\end{array}$ & 2254 & $0.984(0.905$ to 1.070$)$ & $0.101 \mathrm{NS}$ \\
\hline \multicolumn{5}{|c|}{ Meta-analysis of current study and McDowall's $1980-2$ study: } \\
\hline & Road transport drivers & 22665 & $1.030(1.004$ to 1.058$)$ & $0.076 \mathrm{NS}$ \\
\hline & Welders & 4862 & $1.026(0.969$ to 1.086$)$ & $0.337 \mathrm{NS}$ \\
\hline & Railway workers & 3849 & $1.048(0.984$ to 1.117$)$ & $0.862 \mathrm{NS}$ \\
\hline & Medical radiographers & 115 & $1.018(0.694$ to 1.493$)$ & $0.849 \mathrm{NS}$ \\
\hline
\end{tabular}

$\star \mathrm{P}<0.05$.

$\dagger 1990$ Standard occupational classification ${ }^{11}$ used for current study; 1980 classification of occupations ${ }^{13}$ used for McDowall's study. †Current study includes tobacco and process operatives not elsewhere classified. 
$(P=0.19)$. This was confirmed by logistic regression analysis of the sex ratio of children of butchers in relation to year of birth for the entire period 1950-89, which showed no significant trend, the odds ratio for change with year being 1.003 (95\% CI 0.993 to 1.012 ), $\mathrm{P}=0.59$, indicating that the ratio of the probability of having a boy to that of having a girl is, on average, 1.003 times that of the preceding year. However, as the $95 \% \mathrm{CI}$ included 1.0 , the observed numbers of boys and girls were consistent with a lack of any underlying trend in this ratio.

A complete list of sex ratios for the cohort, by the occupational category of the father, including those groups not presented in the tables, is available from us on request.

\section{Discussion}

As the sex ratio among the 10516 live births excluded from the analysis because of lack of information on the fathers' occupations was 1.049 (95\% CI 1.009 to 1.090 ), not significantly different from that for the rest of the study cohort, it is unlikely that their exclusion has biased the results. Some misclassification will have occurred, as the occupation of the father, as recorded on the child's birth certificate, may not have been his occupation before the child's conception. Misclassification may also occur as a result of inaccuracies in the reporting of paternal occupation on the birth certificate, especially as a proportion of births are registered by someone other than the father. ${ }^{14}$ Also, the coding system used to classify occupations is based on the activity carried out by the worker rather than the industry in which he is employed, ${ }^{11}$ and in some cases the industry rather than the activity would be expected to be associated with exposures. Within a particular occupation or industry, there is likely to have been a wide range of exposures, which will have changed over the period considered. ${ }^{15}$

The study showed that children born to fathers in 11 occupational categories out of 367 (3\%) had children with a sex ratio significantly different from that for the rest of the cohort at the $5 \%$ significance level (table 1 ). This is less than the 18 categories which would be expected to seem to be significant at this level by chance alone under the null hypothesis, assuming the same binomial distribution of sexes in all occupation categories. Two occupational categories were significant at the $1 \%$ level, again fewer than the three to four expected and no result was more extreme than this. Hence there was little evidence for effects of occupational exposures on the sex ratio. However, the study covered a 40 year period during which the exposures and lifestyles associated with specific occupations may have changed.

In his study of the $10 \%$ sample of children born in 1980-2, McDowall ${ }^{1}$ found that children born to fathers in 10 out of 350 occupational categories $(2.9 \%)$ had a sex ratio which was significantly different from the national sex ratio at the $5 \%$ level, whereas 17 to 18 occupational categories would be expected to have a significantly different sex ratio at this level by chance alone.

Only one occupational category, butchers and meat cutters, had children with a sex ratio significantly different from the rest of the cohort in both studies: 1.210 , (95\% CI 1.079 to 1.357) in McDowall's study and 1.193, (95\% CI 1.071 to 1.329 ) in the present study. Again, this is consistent with what would be expected by chance: out of 10 occupational categories, the number expected to seem to be significant at the $5 \%$ level by chance is 0.5 and, with exact binomial methods, this corresponds to a $40 \%$ chance that at least one category will seem to be significant in both studies by chance alone under the null hypothesis. There was no evidence to support the suggestion that the sex ratio of the children of butchers was associated with the different growth hormones used in cattle in different periods. ${ }^{6}$

Both studies found fewer significant categories than would be expected by chance alone. Assuming the underlying distribution to be binomial, the probability of observing 11 or fewer significant occupational categories out of 367 at the $5 \%$ level, as in the present study, is 0.043 and the probability of observing 10 or fewer out of 350 , as in McDowall's study, is 0.035 . Overall these results support the hypothesis that the distribution of the sexes has less variance than the binomial. ${ }^{16}$ This phenomenon has been found not only in a subset of 16039 children from the Cumbrian cohort among whom families of two live born children were significantly more likely to have one boy and one girl than expected under the binomial distribution, ${ }^{15}$ but also in a cohort of 160317 children $^{17}{ }^{18}$ who were more likely to be in completed families if the last two children were of opposite sexes. Taken together, these studies imply that the assumption of independence implicit in a binomial model of the distribution of the sexes is not valid-that is, siblings are more likely to be of different sexes rather than the same sex. As a result of this, reported significance levels are likely to be an underestimate.

McDowall ${ }^{1}$ highlighted 26 fathers' occupations from a 1978 study of all births in England and Wales in 1978 and 17 fathers' occupations from a similar study of births in 1931, which seem to be those for which children have unusually high or low sex ratios although none are in fact significantly different from the sex ratio for the rest of the cohort. None of these occupations is represented among the occupational categories in table 1 that were found in the present study to produce children with a significantly higher or lower sex ratio.

Studies combining occupational categories with similar exposures may be more likely to show consistent changes in the sex ratio. ${ }^{89}$ None of the groups with a lowered sex ratio to which McDowall drew attention had a significantly lowered sex ratio either in our study or in a meta-analysis combining the two studies (table 2). However, we noted in an earlier similar meta-analysis ${ }^{9}$ that children of professional drivers had a significantly lower sex ratio, that study used a wider classification of drivers than 
the current study, including not only road transport drivers but also drivers of agricultural and constructional machines, ambulance men, roundsmen, and driving instructors, which shows the importance of including all groups with similar exposures.

Several studies reporting altered sex ratios are of selected small groups rather than complete population cohorts or unbiased samples from such cohorts. ${ }^{2357}$ Many of these groups could not be considered in the present study. Unusually low sex ratios have been reported in the 157 children of 87 anaesthetists in Sheffield, United Kingdom 5 (0.764 (95\% CI 0.549 to 1.060 )) and in the 130 children of 58 abalone divers in Australia ${ }^{3}$ (0.529 (95\% CI 0.361 to 0.769 )). There were insufficient numbers in the present study for valid comparisons: fathers of only six children (five of whom were boys) were recorded as anaesthetists and fathers of only 25 children (14 of whom were boys) were recorded as divers. An unusually low sex ratio (0.616 (95\% CI 0.429 to 0.878$)$ ) was found in 139 children of carbon setters in Washington, United States, ${ }^{7}$ but neither this term nor its homologues, anode setter and carbon changer, appeared as occupations of Cumbrian fathers; these terms refer to occupations of aluminium workers and the word aluminium did not appear either. In a study of 222 children of 111 fathers, Snyder found an unusually low sex ratio $(0.593$ ( $95 \%$ CI 0.379 to 0.916)) in 94 children whose fathers flew fighter planes before they were conceived, but a high sex ratio ( 1.560 (95\% CI 1.080 to 2.273 )) among the rest 128 children whose fathers flew other types of planes or did not fly in the immediate preconception period. ${ }^{4}$ It was not possible to compare with these results as we had no information on the types of planes flown by those fathers whose occupation was pilot. There were similar difficulties in estimating the sex ratios for these groups from McDowall's study. ${ }^{13}$

James ${ }^{19}$ has speculated that welders might be more likely to produce an excess of girls due to exposure to heat, which may result in poor sperm quality and low testosterone concentrations. Bernstein ${ }^{2}$ has claimed that men in "masculine" occupations are more likely to father boys, although these masculine occupations were not clearly specified and little supporting numerical evidence was presented. The current study does not support either of these theories.

If the distribution of the sexes at birth shows less variance than the binomial, then reports of altered sex ratios are more significant than indicated by statistical tests such as $\chi^{2}$ or logistic regression. However, there is the possibility that, in some previous studies, occupational groups may have been identified for analysis because of their altered sex ratios, thus invalidating statistical tests of their significance. The publications of altered sex ratios may be biased in that studies reporting significant associations may be more likely to be published. ${ }^{20}$ Further, some of these studies were under ascertained. ${ }^{35}$ In small groups which contain several children from the same family, the sex ratio may be more likely to show extreme values due to correlations between the sex of successive children in a family. ${ }^{16}$ Alternatively, the sex ratio may be influenced by unknown factors, the effects of which average out in large studies carried out over wide geographical regions or long periods, but which may cause notable deviations in small samples localised in space and time. Exploration of such factors would ideally require not only prospective measurements of exposures suspected of being influential, but also a modelling of factors which might affect the distribution of sexes within families: not only family limitation but also possible correlations between the sexes of successive children. ${ }^{17}$

\section{Conclusion}

The present study of Cumbrian births from $1950-89$, combined with a reconsideration of McDowall's study of 1980-2 births throughout England and Wales, shows that the actual incidence of significantly altered sex ratios among children whose fathers work in specific occupations is no more than would be expected by chance assuming a binomial distribution, and may actually be less. There is certainly no evidence for variation of the sex ratio with occupational category, except when those categories sharing the same exposures are combined. Ideally, investigations should be based on occupational exposures measured prospectively, in known periods including that of spermatogenesis, ${ }^{15}$ and analysis should allow for factors influencing the distribution of sexes within families and the possibility of consequent departures from the binomial distribution.

We thank the United Kingdom Coordinating Committee on Cancer Research and Westlakes Research Institute, for funding this work. We are also grateful to the North of England Children's Cancer Research Fund for the ongoing support it gives to the Children's Cancer Research Unit, Newcastle. We thank Mrs Katharine Kirton for technical assistance and for her patience in typing the manuscript. We are grateful to the anonymous referees for their careful reading of the manuscript and their helpful suggestions.

1 McDowall ME. Occupational reproductive epidemiology. Studies of medical and population subjects. London: Her Majesty's Stationary Office, Office of Population Censuses and Surveys, 1985:50.

2 Bernstein ME. Action of genes affecting secondary sex ratio in man. Science 1951;114:181-2.

3 Lyster WR. Altered sex ratio in children of divers. Lancet 1982:ii:152.

4 Snyder RG. Sex ratio of offspring of pilots of high performance military aircraft. Human Biol 1961;33:1-10.

Wyatt R, Murray Wilson A. Children of anaesthetists. $B M$ 1973;i:675

6 Lloyd MM, Lyster WR, Lloyd OL. Birth sex ratios and prostatic cancer in butchers. Lancet 1987; i:561

7 Milham S. Unusual sex ratio of births to carbon setter fathers. Am F Ind Med 1993;23:829-31.

8 Lyster WR, Lloyd MM, Lloyd OL. Low sex ratio in children of men in alcohol-related occupations. $\mathcal{F} R$ Coll Physicians of men in alcohol-relat

9 Dickinson HO, Parker L. Do alcohol and lead change the Dickinson HO, Parker L. Do alcohol and

10 Parker L, Smith J, Dickinson H, Binks K, Scott L McElvenny $D$, et al. The creation of a database of children of workers at a nuclear facility - an exercise in record linkage. Appl Occup Environ Hyg 1997;12;40-5.

11 Office of Population Censuses and Surveys. Standard occupational classification. Vols 1, 2, 3. London: Her Majesty's Stationary Office, OPCS, 1990.

12 StataCorp. Stata statistical software: release 4.0. College Station, TX: Stata Corporation, 1995

13 Classification of Occupations and coding index. Office of Population Censuses and Surveys. London:HMSO, 1980.

14 Shaw M, Malcoe LH, Croen LA, Smith DF. An assessment of error in parental occupation from the birth certificate. Am $\mathcal{F}$ Epidemiol 1990;131:1072-9. 
15 Dickinson HO, Parker L, Binks K, Wakeford R, Smith J. The sex ratio of children in relation to paternal preconceptional radiation dose: a study in Cumbria, northern England $f$ Epidemiol Community Health 1996;50:645-52.

16 Daly F. The probability of a boy: sharpening the binomial. Mathematical Scientist 1990;15:114-23.

17 Edwards AWF. Sex-ratio data analysed independently of family limitation. Ann Hum Genet 1966;29:337-46.
18 Edwards AWF. A factorial analysis of sex ratio data. Ann Hum Genet 1961;25:117-21.

19 James WH. Sex ratio of offspring as a criterion of occupational hazard, with reference to welding. Scand $f$ Work Environ Health 1994;20:466-7.

20 Easterbrook PJ, Berlin JA, Gopalan R, Matthews DR. Publication bias in clinical research. Lancet 1991;337:867-

\section{Occupational and Environmental Medicine - http://www.occenvmed.com}

Visitors to the world wide web can now access Occupational and Environmental Medicine either through the BMJ Publishing Group's home page (http://www.bmjpg.com) or directly by using its individual URL (http://www.occenvmed.com). There they will find the following:

- Current contents list for the journal

- Contents lists of previous issues

- Members of the editorial board

- Subscribers' information

- Instructions for authors

- Details of reprint services.

A hotlink gives access to:

- BMJ Publishing Group home page

- British Medical Association website

- Online books catalogue

- BMJ Publishing Group books.

The web site is at a preliminary stage and there are plans to develop it into a more sophisticated site. Suggestions from visitors about features they would like to see are welcomed. They can be left via the opening page of the BMJ Publishing Group site or, alternatively, via the journal page, through "about this site". 